\title{
The mammalian mitogen activated protein kinase network
}

\author{
P Lenormand
}

The families of MAP kinases cascades (mitogen activated protein kinases) form major signalling systems by which cells transduce extracellular signals into cellular responses. Studying the regulation of these MAP kinase signalling pathways is of utmost importance in the understanding of the triggering of cell proliferation versus cell differentiation and the responses of the cell to stress or osmotic factors.

This review will describe in detail the archetypal MAP kinase cascade (Raf-MEKERK); it will present the more recently discovered MAP kinase cascades (SAPK and p38) and provide some indications on the regulation of this network of signalling pathways. The scope of the review is not to provide an exhaustive listing of all aspects of research in this field; it aims rather to provide a basis for readers unfamiliar with the subject to scrutinise specific points of interest. Special attention will be given to introduce clearly the nomenclature of mammalian MAP kinase cascades, since it is often confusing with up to five names being used for the same mammalian enzyme. Readers requiring more detailed information on the MAP kinase cascades are referred to other recent reviews. ${ }^{1-5}$

\section{Importance of protein phosphorylation in cell signalling}

Phosphorylation is a reversible means of covalently modifying proteins. The phosphate group being added is highly hydroxylated and negatively charged; thus it is sterically large and able to alter markedly the tridimensional conformation of proteins. Phosphorylation may be permanent and necessary for correct folding of many proteins. Reversible phosphorylation consists of the addition of a phosphate from ATP by a specific protein kinase, and subsequent removal of this phosphate through a protein phosphatase. Phosphorylation of many enzymes affects their catalytic properties. The importance of protein phosphorylation in regulating cellular activities is illustrated by the large number of protein kinase genes that are present in eukaryotic genomes. The latest estimate is that humans have as many as 2000 conventional protein kinase genes. ${ }^{3}$ It is becoming increasingly obvious that protein phosphatases play a specific role in regulating cellular activities and some aspects of these regulating activities will be dealt with in the final section of this review.
Protein kinases have broadly been classified into two main categories according to the amino acid that they phosphorylate: the tyrosine kinases and the serine/threonine kinases. Recently a new class has been discovered, the dual specificity protein kinases that phosphorylate both tyrosine and serine/threonine residues. Additionally, in bacteria ${ }^{6}$ and yeasts, ${ }^{7}$ histidine kinases have been identified which function as osmosensors. In yeast the histidine kinase osmosensor triggers activation of one of the three yeast MAP kinase cascades. ${ }^{7}$ Each newly cloned kinase can be classified in one of these categories by sequence homology, and thus its specificity rapidly revealed.

\section{The MAP kinase cascade module}

MAP kinases (MAPK) are serine/threonine kinases which are activated by a dual phosphorylation on threonine and tyrosine residues ${ }^{8}$ in a sequence of three amino acids: TXY ( $\mathrm{T}=$ threonine, $\mathrm{Y}=$ tyrosine). ${ }^{9}$ The central amino acid (X) of this triad defines each family of MAP kinase as is indicated in fig 1. Their specific upstream activators, called MAP kinase kinases (MAPKK),${ }^{10}$ constitute a family of dual specific threonine/tyrosine kinases, which in turn are activated by MAP kinase kinase kinases (MAPKKK) which are serine/threonine kinases. ${ }^{11}$ A schematic diagram at the left of fig 1 illustrates the MAP kinase cascade module. There are several families of MAP kinase cascades, and members of each family are conserved among various species such as mammals, frogs, flies, worms, or yeasts (reviewed in ${ }^{1}$ ). This high degree of conservation during evolution points towards a fundamental role for these enzymes in cell physiology.

Theoretical enzymological analyses indicate that an amplification factor of 10 can readily be achieved at each stage of these kinase cascades. $^{3}$ A three protein kinase cascade, such as the MAP kinase cascade, could generate a theoretical amplification of 1000 -fold. This provides an easy means to augment a specific signal received at the cell surface by a relatively small number of receptors. The actual amplification achieved by a MAPK pathway in vivo is not yet known, but experimental evidence shows that binding of less than $5 \%$ of Raf-1 molecules to Ras is sufficient to induce maximum activation of the archetypal MAP kinase ERK (cascade illustrated in fig 1). ${ }^{12}$ As \\ Centre de Biochim
CNRS UMR 134, \\ Parc Valrose \\ 06108 Nice Cedex 2 \\ France
}


Nomenclature of the MAP kinase network

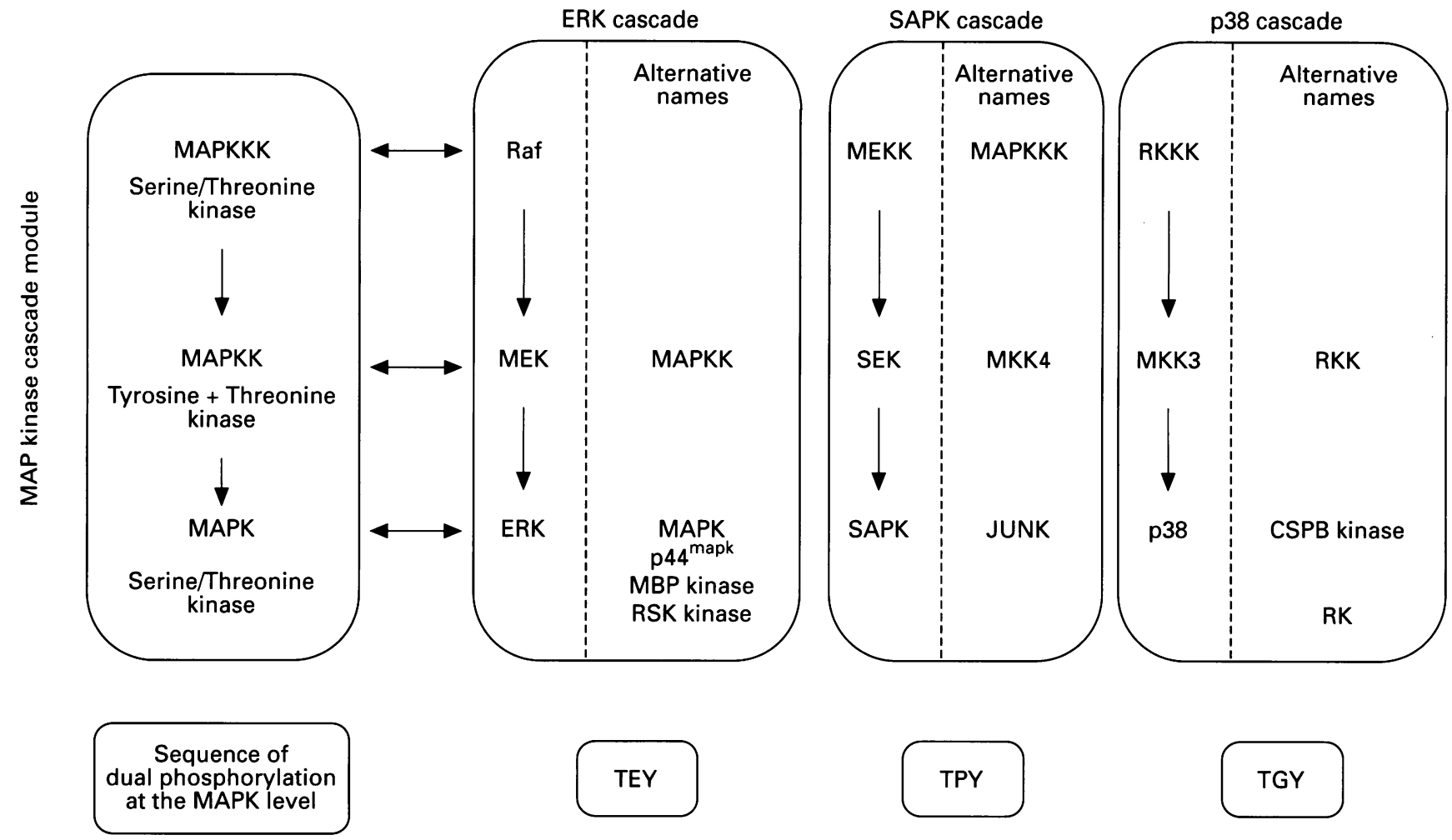

Figure 1 Diagram indicating the nomenclature of the mammalian MAP kinase network. On the left are represented the three levels of the MAP kinase cascade module. Each box represents a cascade and provides alternative names for each step. At the bottom is indicated the amino acid sequence of the phosphorylation sites of the MAPKs ( $T=$ threonine; $Y=$ tyrosine; $E=$ glutamic acid; $G=$ glycine; $P=$ proline).

will be described later, activation of the ERK cascade is an absolute requirement for growth factor mediated cell division. Therefore it may be expected that any deregulation of the signalling component leading to ERK activation would have a profound effect on cell proliferation because of signal amplification by the cascade. For analytical purposes, amplification of the signal at the end of the cascade may prove to be a useful tool for detecting aberrant cellular pathologies initiated by undetectable abnormal regulation of an upstream component.

\section{Nomenclature}

While searching for cytoplasmic substrates of tyrosine kinase receptors, Ray and Sturgill were the first to purify two proteins of $42 \mathrm{kDa}$ and $44 \mathrm{kDa}$ phosphorylated on tyrosine and threonine residues when 3T3-L1 adipocytes were stimulated by insulin. ${ }^{813}$ The preferential substrate of these proteins was the brain $\mathbf{M i}$ crotubule Associated Protein 2, and thus they were named MAP kinase (mapk). ${ }^{813}$ At the same time, other laboratories working with these $\mathrm{p} 42^{\text {mapk }}$ and $\mathrm{p} 44^{\text {mapk }}$ gave the following names to the same enzymes: MBP kinase (Myelin Basic Protein) kinase ${ }^{1415}$ and RSK kinase (90 kDa Ribosomal S6 Kinase-kinase). ${ }^{16}$

As numerous agonists were able to stimulate MAP kinase activity, Sturgill and Weber proposed that the same acronym MAP kinase could stand for Mitogen Activated Protein kinase. Cobb and colleagues ${ }^{1718}$ then identified the cDNAs corresponding to several isoforms of the MAP kinase proteins and named them ERK, for Extracellularly Regulated Kinases (ERK1 for the p44 $4^{\text {mapk }}$, ERK2 for the $\mathrm{p} 42^{\text {mapk }}$ ).

Accordingly, the same protein may be called MAP kinase, ERK1, p44 ${ }^{\text {mapk }}$, MBP kinase, and RSK kinase. Similar confusion occurred later with the direct upstream activator of ERK which was named MAP kinase kinase (MAPKK), ${ }^{10}$ or MEK for "MAP or ERK Kinase" in an attempt to reconcile the two acronyms MAP and ERK. ${ }^{19}$

Recently, two other families of enzymes presenting some homologies to ERKs have been cloned and termed SAPK for Stress Activated Protein Kinases ${ }^{2021}$ and p38. ${ }^{22}$ Their activation is also achieved by dual specificity threonine/ tyrosine kinases presenting homologies to the ERK activator. ${ }^{2324}$ Thus a reasonable consensus exists at the time of writing for calling "MAP kinase cascade" a protein kinase cascade of three enzymes activated sequentially as follows: a serine/threonine kinase (MAPKKK) which activates a dual specificity tyrosineserine/threonine kinase (MAPKK), which activates a serine/threonine kinase (MAPK) (fig 1).

MAPK (interchangeably MAP kinase) is thus the generic name of the third member of each cascade, whereas the name ERK is reserved for the third enzyme of one of the MAP cascades, the Raf-MEK-ERK cascade. Figure 2 gives a synopsis of the actual nomenclature used for the three mammalian MAP kinase cascades and provides alternative names that can be encountered in published reports. The names may correspond to isoforms or enzymes 


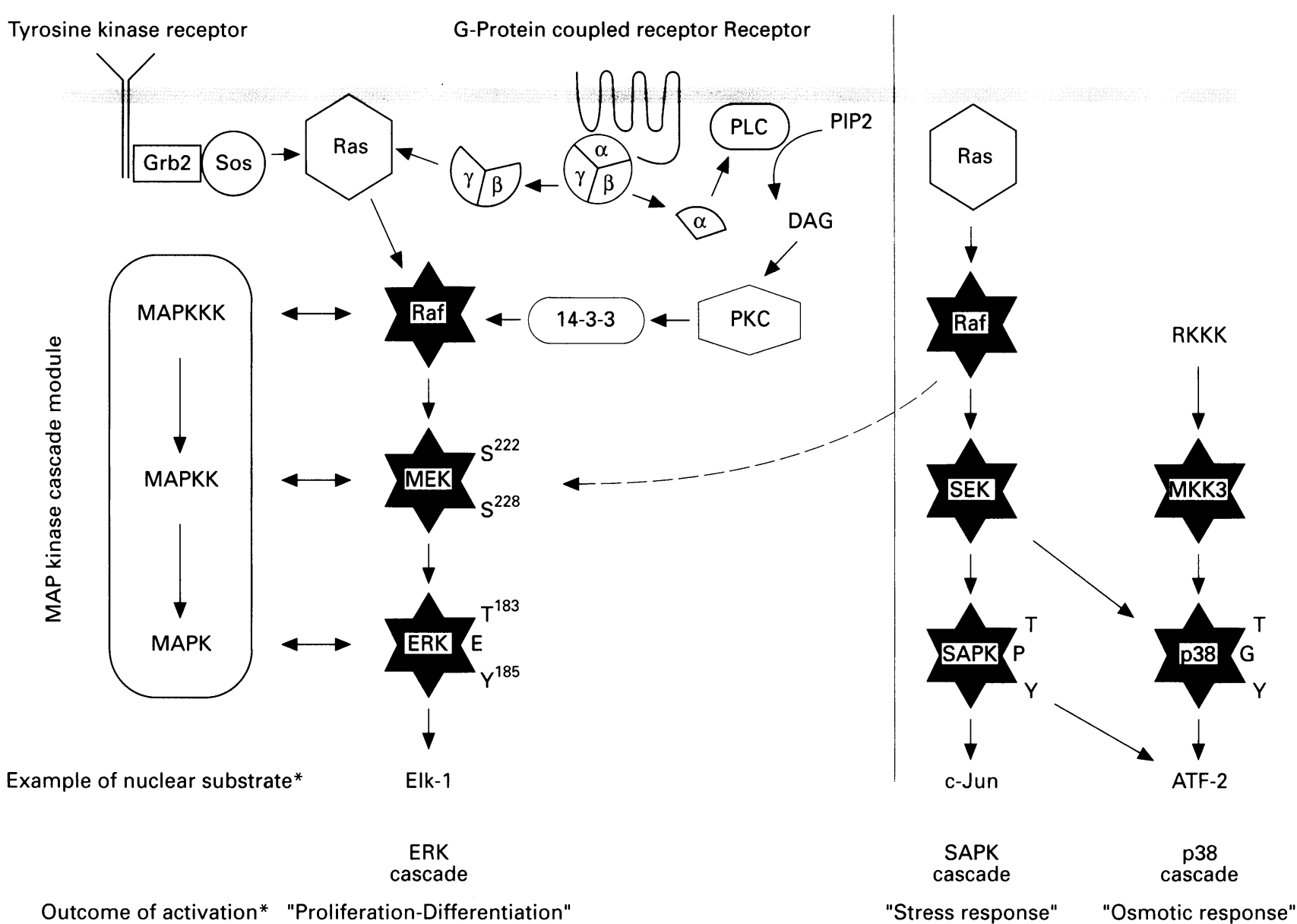

Figure 2 Schematic representation of the identified and putative signalling pathways leading to activation of the three MAP kinase cascades. The black stars represent cloned members of the MAP kinase cascades. Known phosphorylation sites are indicated on the left of the stars. Arrows represent direct activation or protein-protein interactions; see text for details.

* Indication of the cellular responses resulting from the activation of these cascades should be interpreted with care, as crosstalk and multiple activation occur, and some responses may be cell specific.

from different species, and thus a precise equivalence between the names of each isoenzyme is still lacking.

\section{Activation of the Raf-MEK-ERK cascade, the archetypal MAP kinase cascade}

ACTIVATION BY TYROSINE KINASE RECEPTORS (TKR)

Following ligand binding, TKRs dimerise and transphosphorylation occurs on several tyrosine residues of the receptor. Src homology 2 (SH2) domain containing proteins are recruited to these phosphorylated tyrosine residues (reviewed in ${ }^{25}$ ). Binding specificity for each $\mathrm{SH} 2$ domain is provided by the four amino acids upstream of the tyrosine. ${ }^{26}$ Among the numerous $\mathrm{SH} 2$ proteins recruited, the adaptator protein Grb2 leads to activation of the Raf-MEKERK pathway, at least in the case of the EGF (epidermal growth factor) and PDGF (platelet derived growth factor) pathways. ${ }^{25} \mathrm{Grb} 2$ has no intrinsic catalytic activity; it is composed of one $\mathrm{SH} 2$ and two $\mathrm{SH} 3$ domains which promote protein-protein interactions. In this case, the role of Grb2 is solely to recruit proteins bound to its $\mathrm{SH} 3$ domain (Src homology 3), such as the Ras guanine-nucleotide exchange factor, Sos, to the phosphorylated receptor bound to its $\mathrm{SH} 2$ domain. The complex Grb2-Sos is brought to the membrane where Sos interaction with Ras-GDP catalyses the dissociation of GDP from Ras allowing GTP loading and activation of Ras. Then by direct interaction with Ras-GTP, Raf-1 is brought to the membrane ${ }^{127-30}$ where it is likely to be activated by another mechanism which may involve phosphorylation. At present this specific issue is not resolved and two groups have shown recently that the targeting of Raf to the membrane was sufficient to induce Raf activation fully. $^{3132}$ Activated Raf-1 phosphorylates $\mathrm{MEK}^{33}$ on two serine residues S222 and S228. ${ }^{34}$ In turn MEK phosphorylates ERK on a tyrosine (Y183) and a threonine residue (T185) in the sequence TEY $\left(\mathrm{E}=\right.$ glutamic acid). ${ }^{13}$

An alternative pathway to transmit Ras activation to MEK is thought to involve MEK kinase (MEKK) ${ }^{35}$ which phosphorylates MEK on the same sites as Raf. Furthermore, it appears that Ras may have a third effector, PI3 kinase, ${ }^{36}$ and thus activated Ras could exert a multiplicity of effects. Understanding all the cellular signalling pathways induced by Ras is a great challenge for future research; matters are complicated by the existence of three isoforms of Ras in each cell: H-Ras-1, K-Ras-2, and $\mathrm{N}$-Ras (reviewed in ${ }^{37}$ ). What is the rationale for having three isoforms in one cell? How many direct partners interact with Ras? The contribution of multiple Ras functions to 
mammalian cell transformation has recently been demonstrated. ${ }^{38}$

ERK1 and ERK2 are widely expressed in most cell types, and in virtually all cells these two isoforms are coordinately regulated and display the same substrate specificity. Hence it is not understood why cells need both isoforms. ${ }^{39}$ ERK1 and ERK2 have been shown to phosphorylate numerous substrates on the consensus site PXS/TP (reviewed in ${ }^{1}$ ), but in vitro many kinases show an apparently broader substrate specificity; it is thus difficult to identify unambiguously substrates of ERK in vivo. Putative in vivo substrates of ERK include surface receptors, cytosolic protein, and nuclear proteins. ${ }^{1}$

One of the best candidates for nuclear targets of ERK is the transcription factor Elk-1 (also named p62 $\left.{ }^{\mathrm{TCF}}\right) .^{40-42}$ ERK phosphorylates Elk1 on identical sites in vitro and in vivo. Elk-1 plays an essential role in increasing the rate of transcription of many immediate early genes such as c-Fos (reviewed in ${ }^{43}$ ). Elk-1 interacts with SRF (serum response factor) and forms a ternary complex with an SRF dimer. ${ }^{44}$ The phosphorylation of ELK on the sites phosphorylated by ERK has been shown to increase the transcription in vitro of genes containing an SRE (Serum Response Element, binding site for SRF). ${ }^{45}$

In quiescent cells, ERK is cytosolic ${ }^{4647}$ and thus unable to be in contact with nuclear proteins such as Elk-1. Upon mitogenic stimulation, ERK translocates to the nucleus, ${ }^{4647}$ and can thus phosphorylate several nuclear targets. It is noteworthy that $\mathrm{MEK}^{47}$ and $\operatorname{Raf}\left({ }^{48}\right.$ and Lenormand $\mathrm{P}$, personal communication) are exclusively located in the cytoplasm and Ras is membrane bound following specific posttranslational modifications at the $\mathrm{C}$ terminus (reviewed in ${ }^{49}$ ); thus ERK is the first member of this MAP kinase cascade able to translocate and transmit extracellular signals to the nucleus.

Another means of transmitting signals from the Ras-MEK-ERK cascade to the nucleus is performed by ERK activation of the cytosolic kinase $\mathrm{p} 90^{\mathrm{RSK}}$ ( $\mathrm{p} 90$ ribosomal S6 kinase), which in turn can translocate to the nucleus upon stimulation. ${ }^{46}$ The mechanism of nuclear translocation of ERK is not understood as ERK does not possess nuclear localisation sequences (NLS), and we have shown in this laboratory that the nuclear translocation of ERK occurs even when the two phosphorylation sites are mutated and the kinase is no longer activatable. ${ }^{47}$ As will be discussed later, nuclear translocation of ERK is thought to be a critical step in triggering cell proliferation or differentiation; thus understanding the mechanism of this translocation will prove to be very important.

\section{ACTIVATION BY NON-TYROSINE-KINASE}

RECEPTORS

Many hormones and neurotransmitters acting through $G$ protein coupled receptors also activate the Raf-MEK-ERK pathway by a mechanism that involves Ras activation. It has been demonstrated that the thrombin, muscarinic acetylcholine $M 2$, and $\alpha_{2}$ adrenergic receptors activate Ras (conversion from Ras-GDP to Ras-GTP). ${ }^{50}$ The link by which the G protein coupled receptors activate Ras is not at present well established, and may involve proteins of the shc, src family, and (or) PTP1D (Syp). It was shown recently that coexpression of the $\beta$ and $\gamma$ subunits of heterotrimeric $\mathrm{G}$ proteins was able to activate Ras. ${ }^{51}$

Many $\mathrm{G}$ protein coupled receptors activate protein kinase C (PLC) and ERK, but it is not clear yet how PKC activation is transmitted to the Raf-MEK-ERK pathway, nor which isoforms of PKC are implicated. ${ }^{1}$ One report indicates that PKC can activate Raf-1 directly by phosphorylation $^{52}$; alternatively PKC is known readily to phosphorylate members of the 14-33 protein family (reviewed in ${ }^{53}$ ) which have been shown to be bound to Raf. There is some controversy as to whether or not the 14-3-3 protein is indeed able to activate Raf. ${ }^{54-57}$ This shows that deciphering the molecular events leading to Ras and (or) Raf activation will be an area of intense research.

\section{Roles of the Raf-MEK-ERK cascade}

Cells express many types of tyrosine kinase receptors at their surface. Interestingly only some of them can induce cell proliferation (or cell differentiation in a different cell context). We shall see that the duration of the RafMEK-ERK cascade activation provides clues to understanding the final outcome of the cellular response elicited by various tyrosine kinase receptors.

\section{CELL PROLIFERATION}

The importance of the Raf-MEK-ERK cascade in conducting the mitogenic signal is deduced from an array of data. (1) Transfection of oncogenic forms of Ras or Raf induce the proliferation of many cell lines. ${ }^{38}$ (2) Injection of oncogenic Ras into quiescent fibroblasts is sufficient by itself to stimulate DNA synthesis. ${ }^{5859}$ (3) Expression of constitutively activated forms of MEK, generated by site directed mutagenesis, is sufficient to induce mitogenesis and transformation in fibroblasts. ${ }^{60-62}$ Constitutively active MEK1 mutants were generated by replacing the two serines that are the sites of activation by Raf by negatively active amino acids that mimic the negative charge brought by the phosphorylation (S222D and S228D, or S222E and S228E; $\mathrm{D}=$ Aspartic acid, $\mathrm{E}=$ glutamic acid). (4) The dominant negative form of ERK can block mitogenic signalling. ${ }^{63}$ These dominant negative forms are generated by mutation of the phosphorylation sites (T183 or Y185) or mutation of the ATP binding site. The dominant negative forms of ERK are only effective when highly expressed in a cell, and the mechanism of their action is not understood; they may act by making stable complexes with MEK. ${ }^{63}$

In most cell types, many agonists stimulate ERK (reviewed in ${ }^{1}$ ), but there are several 
noticeable differences in the pattern of ERK activation according to the mitogenic potential of these agonists. For example in CCL39 fibroblasts it has been shown that non-mitogenic stimuli activate ERK in a transient manner (maximum of activation between 10 and 30 minutes), whereas mitogenic stimuli induce a second phase of activation that persists for hours. ${ }^{64}$ In addition, only mitogenic stimuli are able to induce nuclear translocation of ERK. ${ }^{47}$ Thus mitogenic stimuli activate ERK for a long duration and induce its nuclear translocation, which may then induce phosphorylation of transcription factors. In this way several stimuli can activate ERK, but the quantitative difference in ERK activation that they induce (durable versus transitory) is translated into a qualitative difference (phosphorylation of transcription factors or not). Establishing the full cascade of events linking the prolonged ERK activation by mitogenic stimuli to cell proliferation is an immense challenge for future research in this field.

\section{DIFFERENTIATION}

The response of PC12 cells to receptor tyrosine kinase activation has been extensively used as an experimental system to study transduction and how activation of some receptors triggers differentiation, while the activation of others leads to proliferation. Treatment of PC12 cells with nerve growth factor (NGF) triggers neurite outgrowth and stops cell division, ${ }^{6566}$ whereas treatment with EGF leads to cell proliferation. ${ }^{67}$ ERK activation is sustained for several hours following NGF stimulation, but it is transitory with EGF stimulation. ${ }^{68-70}$ The association of prolonged ERK activation with NGF stimulation of PC12 cells has led to the idea that it is sustained activation of this pathway that leads to differentiation. Confirmation of this theory came from three sets of experiments. (1) in PC1 2 cells, stimulation of the endogenous EGF receptor induces transient activation of ERK and does not lead to differentiation, but overexpression of the EGF receptor leads to EGF dependent differentiation and sustained activation of ERKs. ${ }^{71}$ (2) Expression of constitutively active MEK mutants in PC12 cells induces neurite outgrowth in the absence of differentiating factors. ${ }^{60}$ (3) Dominant negative mutants of ERK block ligand activation of endogenous ERK and stop differentiation of PC12 cells. ${ }^{60}$ These experiments show that ERK activation is necessary and prolonged activation is sufficient to trigger $\mathrm{PC} 12$ cell differentiation. ${ }^{71}$ There is a correlation between sustained activation of ERK induced by NGF and differentiation. Thus, as for ERK involvement in fibroblast proliferation, these experiments lead us to propose in PC12 that the sustained ERK activation induces marked changes in gene expression which induce cell differentiation. In conclusion, one can propose that prolonged ERK activation triggers a cell fate that was preprogrammed in the cell, leading to differentiation in PC12 cells and cell proliferation in fibroblasts.
The newly discovered MAP kinase

\section{families}

STRESS ACTIVATED MAP KINASES: SAPK

In 1991 , Kyriakis et $a l^{72}$ discovered a $54 \mathrm{kDa}$ protein kinase that was phosphorylated on serine, threonine, and tyrosine residues and activated in liver extracts from cycloheximide treated rats. Subsequent protein purification, peptide sequencing, and cDNA cloning revealed a family of closely related stress activated protein kinases (SAPKs) activated by stresses such as heat shock and by inflammatory cytokines such as tumour necrosis factor $\alpha .{ }^{20}$ Independently, other laboratories identified two kinases that phosphorylate the amino terminus of $c$-Fun (on serines 63 and 73) and potentiate $c-\mathcal{F} u n$ transcriptional transactivating activity. ${ }^{7374}$ These enzymes were thus named fun $\mathrm{N}$ terminal kinase: $\mathrm{JNK} 1$ and $\mathrm{JNK} 2{ }^{21} \mathrm{JNK} 1$ is closely related to SAPK $\gamma$, and JNK2 to SAPK $\alpha$. These enzymes constitute a new family of MAP kinases since their activation requires dual phosphorylation on a tyrosine and a threonine residue at the sequence TPY ( $P=$ proline), instead of the sequence TEY required for ERK.

The race to identify the SAPK activator led to the nearly simultaneous discovery of SEK $1^{2324}$ and $M K K 4^{75}$ which are highly homologous. Two initiation codons can potentially be used to start translation of the SAPK activator, and it appears that the proteins engineered for in vitro studies by these two groups differ: SEK1 starts at the first potential initiation codon and is 34 amino acids larger than MKK4. The SAPK activation cascade was further defined by discovering that MEKK is able to activate in vivo and in vitro both $\mathrm{SEK}^{24}$ and MKK4. ${ }^{75}$ Initially MEKK was thought to contribute in parallel with Raf-1 to the activation of MEK, and thus was named MEK kinase (MEKK). ${ }^{35}$ However, MEKK is able to activate both MEK and SEK when highly expressed in a cell line, but upon mild (normal?) activation it solely phosphorylates and activates SEK. ${ }^{2375}$ In fact, it is more likely that MEKK activates the stress pathway of SAPKs (thus SEK) than the mitogenic pathway of ERKs (thus MEK) as expression of MEKK in fibroblasts arrests cell growth ( ${ }^{24}$, and Brunet $\mathrm{A}$, personal communication).

Matters are complicated by the knowledge that both Raf and MEKK can be activated by $\operatorname{Ras}^{3576}$; the action of cofactors in Ras activation must intervene to lead specifically to the activation of one of these two pathways. In addition to Raf and MEKK, it has been shown recently that Ras was able to activate PI3 kinase. ${ }^{36}$ Understanding precisely the events leading to Ras and Raf activation and all the pathways initiated following Ras activation is a great challenge for the future, and for cancer research in particular, as the presence of oncogenic forms of Ras has been found in at least $10 \%$ of all human cancers. ${ }^{37}$

OSMOREGULATED MAP KINASES: p38

Three closely related proteins, p38, RK, and CSBP kinase, were cloned independently in 1994 and belong to a new MAP kinase family, 
as they are activated upon dual phosphorylation of both a tyrosine and a threonine residue in the sequence $T G Y(G=$ glycine $)$.

p38

p38 is a mammalian protein kinase phosphorylated on tyrosine in response to lipopolysaccharide (LPS) that was cloned from peptide sequencing after its purification ${ }^{22}$ and was shown to be closely related to the yeast protein HOG1 ( $S$ cerevisiae). HOG1 lies in a signalling pathway that restores the osmotic gradient across the yeast cell membrane in response to increased external osmolarity. ${ }^{77}$

\section{$R K$}

$\mathrm{RK}$ was cloned after purification of the enzyme that phosphorylated MAPKAP 2 (MAP kinase activated protein 2) upon heat shock or arsenite stimulation, in the absence of ERK activation. ${ }^{78}$ This protein was named RK after its capability to reactivate MAPKAP 2 which is then able to phosphorylate HSP27 (heat shock protein of $27 \mathrm{kDa})$. HSP27 is induced in response to stress $^{79}$ to protect cells against thermal injuries. $^{80}$

\section{CSBP KINASE}

CSBP kinase was identified as the target of a new drug, CSAID (cytokine suppressive antiinflamatory drug), that inhibits inflammation caused by the action of cytokines such as interleukin-1 and tumour necrosis factor (TNF) ${ }^{81}$ CSBP kinase was purified according to its ability to bind to radiolabelled and radiophotoaffinity labelled CSAID. It was thus called CSAID binding protein kinase, CSBP kinase. CSAID blocks the biosynthesis of cytokines through inhibition of the CSBP kinase; it has the extraordinary interest of being the first drug able to block specifically one of the three known MAP kinase cascades.

The three kinases p38, RK, and CSBP kinase represent the same protein and will be referred to in this review as p38. One putative nuclear substrate of $\mathrm{p} 38$ is the transcription factor ATF$2\left({ }^{75}\right.$, and Brunet $\mathrm{A}$, personal communication). One activator of $\mathrm{p} 38$ has been partially purified: RKK (RK kinase) ${ }^{78}$; two others, MKK3 and MKK4, were cloned by polymerase chain reaction (PCR) using degenerated oligonucleotides corresponding to PBS2, the known activator of HOG1 which is the yeast equivalent of p38. ${ }^{75} \mathrm{MKK} 3$ has been shown to activate p38 specifically, whereas MKK4 (=SEK) can also phosphorylate SAPK, as was described in the previous section. ${ }^{2475}$ No upstream activator of MKK3 has yet been cloned but it seems that Ras and Raf are not implicated in the activation of this cascade. ${ }^{78}$ Interestingly if one makes a parallel with the yeast cascade (PBS2 and HOG $1^{77}$ which are highly homologous to MKK3 and p38 respectively), one can envision that an osmosensor capable of triggering the activation of this kinase cascade could be a histidine kinase, a type of kinase unknown in mammalian cells at present. The yeast osmosensor is called $\mathrm{SLN1}^{7}$; its mutational deletion leads to lethality, which can be suppressed by four complementation groups. One suppressor of the SLN1 mutation is HOG1 and another is its activator PBS2. These data clearly indicate that the yeast osmosensor SLN1 activates a kinase cascade similar to the mammalian MKK3-p38 cascade. The two other complementation groups led to the discovery of a cytoplasmic protein homologous to the regulatory domain of the osmosensor SLN1, and of phosphatases. ${ }^{7}$ It remain to be seen whether mammalian proteins homologous to each yeast protein of this osmoregulatory pathway will be found.

\section{Understanding the regulation of the mammalian MAP kinase network}

Studying the regulation of such a complex kinase network is fraught with difficulties. This section will provide some reflections about limitations in interpreting current results, and indicate research trends in this field.

\section{THE DIFFICULTIES IN IDENTIFICATION OF IN} VIVO SUBSTRATE

In vitro the catalytic properties of a kinase are often modified, usually with a reduction in substrate specificity. To identify substrates unambiguously in vivo, one can only correlate in vitro and in vivo phosphorylation at the same sites, but these sites may be phosphorylated in vivo by several kinases. Phosphorylation may also occur on sites that do not affect the function of a particular protein as we can assess it. For example, c-fun was thought to be an in vivo substrate of ERK because ERK was shown to phosphorylate the full $c$ - fun protein readily in vitro. ${ }^{82}$ The significance of this ERK dependent phosphorylation of $c-f u n$ is not understood because $\mathrm{C}$ terminal phosphorylation does not affect $c$-fun transcriptional transactivation. It is now acknowledged that SAPKs (JNKs) are the cellular activators of $c-\mathcal{f u n}$ as they specifically phosphorylate both the serines 63 and 73 implicated in activation of c-fun transcriptional transactivation. ${ }^{83}$

The discovery of the p38 specific inhibitor, CSAID ${ }^{81}$ will allow the specific blocking of this kinase cascade and should permit the identification of specific roles of the cascade in cell physiology. Specific inhibitors of the other MAP kinases may be found, and this would allow us to assess the precise contribution of each cascade in cellular responses to mitogenic and non-mitogenic stimuli or to stress factors. One incentive for finding specific inhibitors of ERK is the possibility of blocking many upstream pathological disorders of this pathway, disorders that often lead to aberrant cell proliferation. For example, it is known that mutations of Ras are implicated in about $70 \%$ of all pancreatic cancers ${ }^{37}$; as blocking ERK activation was shown to stop mitogenicity in fibroblasts, ${ }^{63}$ it would be of interest to test whether this is also true for some types of cancer cells, such as those with constitutively active Ras. 
OVEREXPRESSION OF THE KINASE STUDIED MAY CREATE ARTEFACTUAL EFFECTS

MEKK was named from its ability to activate MEK both in vitro and in vivo when overexpressed in fibroblasts. ${ }^{35}$ Recent work indicates that transfection of MEKK induces both MEK and SEK activation, whereas low expression of MEKK upon conditional induction activates SEK specifically, and not MEK. ${ }^{23245}$ The use of inducible promoters to drive expression of the kinase of interest should be more widely applied. Unfortunately, all available inducible expression vectors present drawbacks such as leaky expression without induction or weak induction, or even secondary effects by the inducer. An alternative strategy is to make fusion proteins with the catalytic domain of the protein of interest and the oestradiol receptor binding domain (ER). In some cases, such as with Raf, the oestradiol binding domain is able to mask the catalytic domain of the kinase, and upon addition of oestradiol the catalytic domain is revealed. ${ }^{84}$ Cell lines expressing this Raf-ER have been established, and it has be shown that addition of oestradiol leads to MEK activation within two minutes and ERK activation within five minutes, the maximum of activation being reached by 30 minutes ( ${ }^{85}$ and Lenormand $\mathrm{P}$, unpublished data).

CELL TYPE SPECIFIC DIFFERENCES

One stimulus may provoke opposite effects in two cell types, which may be the result of marked differences in the differentiation programme engaged. I shall illustrate this complexity by two examples, the response of MAP kinase pathways to osmotic shock, and the role of PKA activation on the Raf-MEK-ERK pathway.

Variability in osmotic shock responses

In some fibroblasts, osmotic shock has no significant effects on ERK activation. ${ }^{22}$ On the contrary, cells of renal origin such as MDCK cells (Madin-Darby canine kidney epithelial cells) respond to hyperosmolarity by activation of Raf, MEK, and ERK. ${ }^{86}$ Clearly fibroblasts are not exposed to the same variations of osmotic pressure as are renal cells; none the less no molecular mechanism can yet explain such differences.

In the cell lines tested so far (mostly fibroblasts), hyperosmolarity modulates both SAPK and $\mathrm{p} 38 .^{202287}$ This can be explained by the fact that p38 and SAPK can be activated by a SEK/MKK $4^{75}$; in addition they could be activated by distinct MAPKKs that are both osmoregulated.

\section{Variability in response to $P K A$ activation}

ERK activation is required for fibroblast cell proliferation, ${ }^{63}$ and it has been appreciated for some time that a rise in CAMP, which activates PKA, inhibits cell proliferation. ${ }^{88}$ In contrast, in dog thyrocytes (cells of epithelial origin) PKA stimulates growth in the absence of ERK stimulation. ${ }^{89}$ The molecular mechanisms explaining these differences are lacking; however progress was obtained by showing in NIH 3T3 fibroblasts that PKA activation inhibits the ERK pathway at the level of Raf1..$^{90-94}$ This effect may result from direct inhibitory phosphorylation of Raf1 by PKA. ${ }^{95}$ However, it has recently been shown in CCL39 fibroblasts that PKA inhibition of ERK, although rapid, is very transient (McKenzie F, personal communication). Finally, in PC12 cells, PKA stimulates ERK activation by NGF instead of blocking it. ${ }^{9697}$

Interestingly, in PC12 cells PKA inhibits Raf activated by NGF. ${ }^{989}$ Thus cAMP activation of ERK would have to be accomplished by Raf independent activation of a distinct MAPKKK such as MEKK, which is activated by a Ras dependent pathway and has been shown to activate $\mathrm{MEK}$ in vitro or when overexpressed. ${ }^{35}$

The different effects of PKA activation on the ERK pathway in fibroblasts, PC12 cells, and thyrocytes provide another illustration of fundamental cell type specific differences. Understanding these differences at the molecular level is a great challenge.

\section{SPECIFICITY IN MAP KINASE ACTIVATION}

In some cell lines the activation of MAP kinase pathways can be kept separated; for example in PC12 cells, NGF activates ERK but not p38, and arsenite activates p38 but not ERKs. ${ }^{78}$

This isolation of one MAP kinase pathway from the others may be due to the specificities of the kinases involved; it may also be helped by arranging the cascades of kinases in complexes. The only example of such complex in MAP kinase signalling is provided by the matingtype pathway in the yeast $S$ cerevisiae. The kinases of this pathway (homologous to MEK and ERK) seem to be held together by a scaffolding protein, STE5. ${ }^{100101}$ Kinases from the two other yeast MAP kinase pathways (one for osmosensing and one dedicated to cell wall biosynthesis) cannot bind to STE5. ${ }^{100}$ STE5 may bring kinases into close proximity to ensure specificity and speed of activation. Several laboratories are searching for mammalian homologues of STE5, but there is no report of success at present.

CROSS TALK BETWEEN MAP KINASE PATHWAYS Negative feedback is a widely used mechanism for signal attenuation and desensitisation, though it is not clear yet whether negative feedback operates in MAP kinase signalling pathways. Activated ERK was shown to phosphorylate SOS, ${ }^{102}$ Raf, $^{103}$ and MEK. ${ }^{104-106}$ It seems that these feedback phosphorylations have little or no effect on MEK and Raf activities, but this lack of effect could be due to our incapacity to measure fine regulation with in vitro studies. Negative feedback by ERK was thought to occur by phosphorylation of the EGF receptor at threonine 669, which does not seem to affect the kinase activity but could increase receptor internalisation. ${ }^{107} 108$ 
Two groups reported that ERK phosphorylates SEK, ${ }^{2475}$ but the significance of this crosstalk among MAP kinase pathways is still not understood.

\section{ROLE OF THE PHOSPHATASES}

It is increasingly obvious that protein phosphatases are involved in the regulation of signal transduction (reviewed in ${ }^{3109110}$ ). ERK activation is biphasic, and some phosphatases are likely to be responsible for both phases of inactivation. The phosphatase responsible for inactivating the first peak of activation is unknown, but for the second phase of activation MKP-1 (MAP kinase phosphatase-1, also called CL100) is a good candidate. ${ }^{111}$ It belongs to a new family of dual specificity phosphatases able to dephosphorylate ERK on both the threonine and the tyrosine residue. $\mathrm{MKP}-1$ is an early gene which is not expressed in arrested cells: upon stimulation MKP-1 accumulates after 30 minutes and is nuclear. ${ }^{112}$ It could be responsible for inactivating ERK in the nucleus; none the less its precise role still needs to be well defined since it is now apparent that a family of MKP-1-like proteins exists which may be specific inactivators of each MAP kinase. However, ERK kinase inactivation is often too rapid to be explained by the MKP-1 family of proteins. ${ }^{113}$ Recent data suggest that rapid inactivation of the MAP cascade at the level of ERK is mediated by PP2A (protein phosphatase $2 \mathrm{~A}$ ) which removes phosphothreonine and an as yet unidentified tyrosine phosphatase distinct from MKP-1. ${ }^{114}$

\section{Concluding remarks}

In recent years, signalling by MAP kinase has blossomed into three distinct kinase cascades. The crossover points between individual members of these cascades, and hence the specificity of agonist activation of each cascade, remain to be defined. One of the greatest challenges is to identify the specific in vivo substrates of each of the three end members of the ERK, SAPK, and p38 cascades. For pathologists, fundamental research on this pathway will provide tools that may permit the correlation of the abberant status of an MAP kinase pathway with pathophysiological conditions. For example it is at present impossible to evaluate Ras activation in one cell, and it may remain impossible because of the small percentage of GTP-Ras sufficient to induce full activation of ERK. None the less signal magnification may render the indirect assessment of Ras activation possible from the development of new tools such as monoclonal antibodies that specifically recognise phosphorylated ERK (Nishida E, personal communication). With these antibodies, it is possible to evaluate the subcellular localisation of activated ERK. Will it be possible to distinguish between aberrantly proliferating cells and normal ones by detecting nuclear accumulation of activated ERK?

I am most grateful to Drs A Brunet, N Rivard, J-M Brondello and $F$ McKenzie critical reading of the manuscript; special thanks to Drs J Lavoie and G L'Allemain for providing valuable information and DrJ Pouysségur for excellent scientific support.
1 L'Allemain G. Deciphering the MAP kinase pathway. Prog Growth Factor Res 1994;5:291-334.

2 Marshall CJ. Specificity of receptor tyrosine kinase signaling: transient versus sustained extracellular signal-regulated kinase activation. Cell 1995;80:179-85.

3 Hunter T. Protein kinases and phosphatases: the yin and yang of protein phosphorylation and signaling. Cell 1995 80:225-36.

4 Cooper JA. Straight and narrow or tortuous and intersecting? Curr Biol 1994;4:1118-21.

5 Cano E, Mahadevan LC. Paralled signal processing among mammalian MAPKS. Trends Biochem Sci 1995;20:117-

6 Bourret RB, Hess JF, Borkovich KA, Pakula AA, Simon MI. Protein phosphorylation in chemotaxis and twocomponent regulatory systems of bacteria. $\mathcal{F}$ Biol Chem 1989;264:7085-8.

7 Maeda T, Wurgler-Murphy SM, Saito H. A two-component system that regulates an osmosensing MAP kinase cascade in yeast. Nature 1994;369:242-5.

8 Ray LB, Sturgill TW. Rapid stimulation by insulin of a serine/threonine kinase in 3T3-L1 adipocytes that phosphorylates microtubule-associated protein 2 in vitro. Proc Natl Acad Sci USA 1987;84:1502-6.

9 Payne DM, Rossomando AJ, Martino P, Erickson AK, Her $\mathrm{JH}$, Shabanowtiz J. et al. Identification of the regulatory phosphorylation sites in $\mathrm{pp} 42 /$ mitogen-activated protein kinase (MAP kinases). EMBO $f$ 1991;10:885-92.

10 Matsuda S, Kosako H, Takenaka K, Moriyama K, Sakai $\mathrm{H}$, Akiyama $\mathrm{T}$, et al. Xenopus MAP kinase activator: identification and function as a key intermediate in the phosphorylation cascade. EMBO ff 1992;11:973-82.

12 Lange-Carter CA, Pleiman CM, Gardner AM, Blumer KJ, Johnson GL. MEK kinase and Raf define a divergence in the MAP kinase regulatory network. Science 1993;260 318-9.

12 Hallberg B, Rayter SI, Downward J. Interaction of ras and raf in intact mammalian cells upon extracellular stimulation. $\mathcal{f}$ Biol Chem 1993;269:3913-6.

13 Ray LB, Sturgill TW. Insulin-stimulated microtubule-associated protein kinase is phosphorylated on tyrosine and threonine in vivo. Proc Natl Acad Sci USA 1988;85: 3753-7.

14 Pelech SL, Tombes RM, Meijer L, Krebs EG. Activation of myelin basic protein kinases during echinoderm oocyte maturation and egg fertilization. Dev Biol 1988;130:2836

15 Ahn N, Krebs E. Evidence for an epidermal growth factorstimulated protein kinase cascade in swiss $3 \mathrm{~T} 3$ cells. $\mathcal{f}$ Biol Chem 1990;265:11495-501.

16 Chung J, Pelech S, Blenis J. Mitogen-activated Swiss Mouse 3T3 RSK kinases I and II are related to pp44 mapk from sea star oocytes and participate in the regulation of pp90 RSK

17 Boulton TG, Yancopoulos GD, Gregory JS, Slaughter C, Moomaw C, Hsu J, et al. An insulin-stimulated protein kinase similar to yeast kinases involved in cell cycle control. Science 1990;249:64-7.

18 Boulton TG, Nye SH, Robbins DJ, Ip NY, Radziejewska E, Morgenbesser SD, et al. ERKs: a family of proteinserine/threonine kinases that are activated and tyrosine phosphorylated in response to insulin and NGF. Cell 1991;65:663-75.

19 Crews CM, Alessandrini A, Erikson RL. The primary structure of MEL, a protein kinase that phosphorylates the ERK gene product. Science 1992;258:478-80.

20 Kyriakis JM, Banerjee P, Nikolakaki E, Dai T, Rubie EA Ahmad MF, et al. The stress-activated protein kinase subfamily of $c$ - fun kinases. Nature 1994;369:156-60.

21 Dérijard B, Hibi M, Wu I-H, Barrett T, Su B, Deng T, et al. JNK1: a protein kinase stimulated by UV light and Ha-Ras that binds and phosphorylates and the c-jun activation domain. Cell 1994;76:1025-37.

22 Han J, Lee J-D, Bibbs L, Ulevitch RJ. A MAP kinase targeted by endotoxin and hyperosmolarity in mammalian cells. Science 1994;265:808-11.

23 Sanchez I, Hughes RT, Mayer BJ, Yee K, Woodgett JR, Avruch J, et al. Role of SAPK/ERK kinase-1 in the stressactivated pathway regulating transcription factor $c$-jun. Nature 1994;372:794-8.

24 Yan M, Dai T, Deak JC, Kyriakis JM, Zon LI, Woodgett $\mathrm{JR}$, et al. Activation of stress-activated protein kinase by MEKK1 phosphorylation of its activator SEK1. Nature MEKK1 phosphorylat

25 Schlessinger J. SH2/SH3 signalling proteins. Curr Opin Genet Dev 1994;4:25-30.

26 Songyang Z, Shoelson SE, McGlade J, Olivier P, Pawson $\mathrm{T}$, Bustelo XR, et al. Specific motifs recognized by the SH2 domains of CSk, 3BP2, fps/fes, GRB-2, HCP, SHC, Syk, and Vav. Mol Cell Biol 1994;14:2777-85.

27 Koide H, Satoh T, Nakafuku M, Kaziro Y. Gtp-dependent association of raf-1 with Ha-Ras: identification of Ras as target downstream of Ras in mammalian cells. Proc Nat Acad Sci USA 1993;90:8683-6.

28 Moodie SA, Willumsen BM, Weber MJ, Wolfman A Complexes of Ras-GTP with Raf-1 and mitogen-activated protein kinase kinase. Science 1993;260:1658-61.

29 Van Aelst L, Barr M, Marcus S, Polverino A, Wigler M Complex formation between Ras and Raf and other Complex formation between Ras and Raf and oth kinases. Proc Natl Acad Sci USA 1993;90:6213-7.

30 Vojtek AB, Hollenberg SM, Cooper JA. Mammalian Ras interacts directly with the serine/threonine kinase Raf Cell 1993;74:505-14. 
31 Stokoe D, Macdonald SG, Cadwallader K, Symons M, Hancock JF. Activation of Raf as a result of recruitmen to the plasma membrane. Science 1994;264:1463-7.

32 Leevers SJ, Paterson HF, Marshall CJ. Requirement for Ras in Raf activation is overcome by targeting Raf to the Ras in Raf activation is overcome by targeting
plasma membrane. Nature 1994;369:411-4.

plasma membrane. Nature 1994;369:411-4.
33 Kyriakis JM, App H, Zhang X, Baneriee P, Brautigan DL, Rapp UR, et al. Raf-1 activates MAP kinase-kinase. Nature Rapp UR, et al. Ra

34 Alessi D, Saito Y, Campbell DG, Cohen P, Sithanandam $\mathrm{P}, \mathrm{Rapp} \mathrm{U}$, et al. Identification of the sites in MAP kinase kinase-1 phosphorylated by $\mathrm{p} 74 \mathrm{raf}-1 . E M B O \mathcal{F} 1994 ; 13$ : 1610-9

35 Lange-Carter CA, Johnson GL. Ras-dependent growth factor regulation of MEK kinase in PC12 cells. Science 1994;265:1458-61.

36 Rodriguez-Viciana P, Warne PH, Dhand R, Vanhaesebroeck B, Gout I, Fry MJ, et al. Phoshaesebroeck B, Gout I, Fry MJ, et al. Phos-
phatidylinositol-3-OH kinase as a direct target of Ras. phatidylinositol-3-OH kinas $1994 ; 370: 527-32$.

37 Barbacid M. Ras genes. Annu Rev Biochem 1987;56:779 827.

38 White MA, Nicolette C, Minden A, Polverino A, Van Aelst $\mathrm{L}$, Karin M, et al. Multiple ras functions can contribute to mammalian cell transformation. Cell 1995;80:533-41.

39 Davis RJ. The motigen-activated protein kinase signal transduction pathway. F Biol Chem 1993;268:14553-6.

40 Marais R, Wynne J. The SRF accessory protein Elk-1 contains a growth factor-regulated transcriptional activation domain. Cell 1993;73:381-93.

41 Hill CS, Marais R, John S, Wynne J, Dalton S, Treisman $R$. Functional analysis of a growth factor-responsive transcription factor complex. Cell 1993;73:395-406.

42 Hipskind RA, Baccarini M, Nordheim A. Transient activation of Raf-1, MEK and ERK2 coincides kinetically with ternary complex factor phosphorylation and immediate-early gene promoter activity in vivo. Mol Bell Biol 1994;14:6219-31.

43 Treishman R. The serum response element. Trends Biochem Sci 1991;17:423-7.

44 Hipskind RA, Rao VN, Mueller CG, Reddy ES, Nordheim A. Ets-related protein Elk-1 is homologous to the $c$-fos A. Ets-related protein Elk-1 is homologous to the

45 Rao VN, Reddy SP. Elk-1 proteins interact with MAP kinases. Oncogene 1994;9:1855-60.

46 Chen TH, Sarnecki C, Blenis J. Nuclear localization and regulation of ERK- and RSK-encoded protein kinases. Mol Cell Biol 1992;12:915-27.

47 Lenormand P, Sardet C, Pagès G, L'Allemain G, Brunet A, Pouysségur J. Growth factors induce nuclear translocation of MAP kinases (p42mapk and p44mapk) but not of their activator MAP kinase kinase ( 445 mapkk) in fibroblasts. F Cell Biol 1993;122:1079-88.

48 Traverse S, Cohen P, Paterson H, Marshall C, Rapp U, Grand RJA. Specific association of activated MAP kinase kinase kinase (Raf) with the plasma membranes of raskinase kinase (Raf) with the plasma membranes of
transformed retinal cells. Oncogene 1992;8:3175-81.

49 Grand RJA, Owen D. The biochemistry of ras p21. Biochem f 1991;279:609-31.

50 Johnson GL, Vaillancourt RR. Sequential protein kinase reactions controlling cell growth and differentiation. Curr Opin Cell Biol 1994;6:230-8.

51 Crespo P, Xu N, Simonds WF, Gutkind JS. Ras-dependen activation of MAP kinase pathway mediated by G-protein beta-gamma subunits. Nature 1994;369:418-20.

52 Kolch W, Heidecker G, Kochs G, Hummel R, Vahidi H, Mischak $\mathrm{H}$, et al. Protein kinase $\mathrm{C}$ alpha activates Raf-1 by direct phosphorylation. Nature 1993;364:249-52.

53 Aitken A. 14-3-3 proteins on the map. Trends Biochem $S_{c i}$ 1995;20:95-7.

54 Freed E, Symons M, Macdonald SG, McCormick F, Ruggieri R. Binding of $14-3-3$ proteins to the protein kinase Raf and effects on its activation. Science 1994;265 $1713-6$

55 Irie K, Gotoh Y, Yashar BM, Errede B, Nishida E, Matsumoto K. Stimulatory effects of yeast and mammalian 14-3-3 proteins on the Raf protein kinase. Science 1994 265:1716-9.

$56 \mathrm{Fu} \mathrm{H}$, Xia K, Pallaq DC, Cui C, Conroy K, Narsimhan RP. et al. Interaction of the protein kinase Raf-1 with 143-3 proteins. Science 1994;266:126-9.

57 Reuther GW, Fu H, Cripe LD, Collier RJ, Pendergast AM. Association of the protein kinases C-Bcr and BcrAM. Association of the protein kinases C-Bcr and BcrAbl with $129-33$.

58 Feramisco JR, Gross M, Kamata T, Rosenberg M, Sweet RW. Microinjection of the oncogene form of the human $\mathrm{H}$-ras (T-24) protein results in rapid proliferation of quiescent cells. Cell 1984;38:109-17.

59 Morris JDH, Price B, Lloyd AC, Self AJ, Marshall CJ, Hall A. Scrape loading of Swiss 3T3 cells with Ras protein rapidly activates protein kinase-C in the absence of phosphoinositide hydrolysis. Oncogene 1989;4:27-31.

60 Cowley S, Paterson H, Kemp P, Marshall CJ. Activation of MAP kinase kinase is both necessary and sufficient for PC12 differentiation and for transformation of NIH 3T3 cells. Cell 1994;77:841-52.

61 Mansour SJ, Matten WT, Hermann AS, Candia JM, Rong $\mathrm{S}$, Fukasawa $\mathrm{K}$, et al. Transformation of mammalian cells by constitutively active MAP kinase kinase. Science 1994; 265:966-70.

62 Brunet A, Pagès G, Pouysségur J. Constitutively active mutants of MAP kinase kinase (MEK1) induce growth mutants of MAP kinase kinase (MEK1) induce growth fibroblasts. Oncogene 1994;9:3379-87.
63 Pagès G. Lenormand P, L'Allemain G, Chambard JC, Meloche $\mathrm{S}$, Pouysségur J. Mitogen-activated protein kinases $\mathrm{p} 42^{\text {mapk }}$ and $\mathrm{p} 44^{\text {mapk }}$ are required for fibroblast proliferation. Proc Natl Acad Sci USA 1993;90:8319-23.

64 Meloche S, Seuwen K, Pagès G, Pouysségur J. Biphasic and synergistic activation of $\mathrm{p} 44^{\text {mapk }}$ (ERK1) by growth factors: correlation between late phase activation and factors: correlation between late phase activa

65 Greene LA, Tischler AS. Establishment of a noradrenergic clonal line of rat adrenal pheochromocytoma cells which respond to nerve growth factor. Proc Natl Acad Sci USA 1976;73:242-8.

66 Tischler AS, Dichter MA, Biales B, DeLellis RA, Wolfe $\mathrm{H}$. Neural properties of cultured human endocrine tumor cells of proposed neural crest origin. Science 1976;192: 902-4.

67 Huff K, End D, Guroff G. Nerve growth factor-induced alterations in the response of PC12 phaechromocytoma cells to epidermal growth factor. 7 Cell Biol 1981;88: 189-98.

68 Heasley LE, Johnon GL. The beta PDGF receptor induces neuronal differentiation of PC12 cells. Mol Biol Cell 1992; 3:545-53.

69 Traverse S, Gomez N, Paterson H, Marshall C, Cohen P. Sustained activation of the mitogen-activated protein
(MAP) kinase cascade may be required for differentiation of PC12 cells. Biochem $\mathcal{F}$ 1992;288:351-5.

70 Nguyen TT, Scimeca J-C, Fillous C, Peraldi P, Carpentier $\mathrm{J}-\mathrm{L}$, Van Obberghen E. Co-regulation of the mitogenactivated protein kinase, extracellular signal-regulated kinase and the $90 \mathrm{kDa}$ ribosomal S6 kinase in PC12 cells. nase and the $90 \mathrm{kDa}$ ribosomal
$\mathcal{F}$ Biol Chem 1993;268:9803-10.

71 Traverse S, Seedorf K, Paterson H, Marshall C, Cohen P, Ullrich A. EGF triggers neuronal differentiation of PC12 cells that overexpress the EGF receptor. Curr Biol 1994; 4:694-701.

72 Kyriakis JM, Brautigan DL, Ingebritsen TS, Avruch J. pp54 microtubule-associated protein-2 kinase requires both tyrosine and serine/threonine phosphorylation for activity. F Biol Chem 1991;266:10043-6.

73 Adler V. Polotskaya A, Wagner F, Kraft AS. Affinitypurified $c$-fun amino-terminal protein kinase requires serine/threonine phosphorylation for activity. $\mathrm{F} \mathrm{Biol} \mathrm{Chem}$ 1992;267:17001-5.

74 Hibi M, Lin A, Smeal T, Minden A, Karin M. Identification of an oncoprotein- and UV-responsive protein kinase that binds and potentiates the $c$ - fun activation domain. Genes Dev 1993;7:2135-48.

75 Dérijard B, Raingeaud J, Barrett T, Wu I-H, Han J, Ulevitch RJ, et al. Independent human MAP kinase signal transduction pathways defined by MEK and MKK isotransduction pathways defined
forms. Science 1995;267:682-5.

77 Hall A. A biochemical function for Ras-at last. Science 1994;264:1413-4

77 Brewster JL, de Valoir Y, Dwyer ND, Winter E, Gustin MC. An osmo-sensing signal transduction pathway in yeast. Science 1993;259:1760-3

78 Rouse J, Cohen P, Trigon S, Morange M, Alonso-Limazares A, Zamanillo D, et al. A novel kinase cascade triggered by stress and heat shock that stimulates MAPKAP kinase- 2 and phosphorylation of the small heat shock proteins. Cell 1994;78:1027-37.

79 Landry J, Chretien P, Lambert H, Hickey E, Weber LA. Heat shock resistance conferred by expression of the Heat shock resistance conferred by expression of the
human hsp 27 gene in rodent cells. $\mathcal{f}$ Cell Biol 1989;109: human

80 Lavoie JN, Gingras BG, Tanguay RM, Landry J. Induction of Chinese hamster HSP27 gene expression in mouse cells confers resistance to heat shock. HSP27 stabilization of the microfilament organization. $f$ Biol Chem 1993;268: 3420-9.

81 Lee JC, Laydon JT, McDonnell PC, Gallagher TF, Kumar $\mathrm{S}$, Green $\mathrm{D}$, et al. A protein kinase involved in the regulation of inflammatory cytokine biosynthesis. Nature regulation of inflam
$1994 ; 372: 739-46$.

82 Pulverer BJ, Kyriakis JM, Avruch J, Nikolakaki E, Woodgett JR. Phosphorylation of $c$-jun mediated by MAP kinases. Nature 1991;353:670-4.

83 Minden A, Lin A, Smeal T, Derijard B, Cobb M, Davis $\mathrm{R}$, et al. c-jun $\mathrm{N}$-terminal phosphorylation correlates with activation of the JNK subgroup but not the ERK subgroup of mitogen-activated protein kinases. Mol Cell Biol 1994; 14:6683-8.

84 Samuels ML, McMahon M. Inhibition of platelet-derived growth factor-and epithelial growth factor-mediated mitogrowth factor- and epithelial growth factor-mediated mito-
genesis and signaling in 3 T3 cells expressing $\triangle$ Raf-1:ER, genesis and signaling in $3 T 3$ cells expressing $\Delta$ Raf-1:ER,
an estradiol-regulated form of Raf-1. Moll Cell Biol 1994; an estradiol-reg.

85 Samuels ML, Weber MJ, Bishop JM, McMahon M. Conditional transformation of cells and rapid activation of the mitogen-activated protein kinase by an estradioldependent human Raf-1 protein kinase. Mol Cell Biol 1993;13:6241-52.

86 Terada Y, Tomita K, Homma MK, Nonoguchi H, Yang T, Yamada T, et al. Sequential activation of Raf-1 kinase, mitogen-activated protein (MAP) kinase kinase, MAP
kinase, and S6 kinase by hyperosmolarity in renal cells. f Biol Chem 1994;269:31296-301.

87 Galcheva-Gargova Z, Dérijard B, Wu I-H, Davis RJ. An osmosensing signal transduction pathway in mammalian cells. Science 1994;265:806-8.

88 Pastan I, Johnson GS, Anderson WB. Role of cyclic nucleotides in growth control. Ann Rev Biochem 1975;44: 491-522. 
89 Lamy F, Wilkin F, Baptis M, Posada J, Roger PP, Dumont E. Phosphorylation of mitogen-activated protein kinases is involved in the epidermal growth factor and phorbol ester, but not in the thyrotropin/cAMP, thyroid mitogenic pathway. F Biol Chem 1993;268:8398-401.

90 Burgering BMT, Pronk GJ, Vanweeren PC, Chardin P, Bos JL CAMP antagonizes p21(ras)-directed activation Bos JL. CAMP antagonizes p21(ras)-directed activation of extracellular signal-regulated kinase- 2 and phosphorylation of mSos nucleotide exchange factor. EMBO f 1993;12:4

91 Cook SJ, McCormick F. Inhibition by cAMP of Rasdependent activation of raf. Science 1993;262:1069-72.

92 Graves LM, Bornfeldt KE, Raines EW, Potts BC, Macdonald SG, Ross R, et al. Protein kinase-A antagonizes platelet-derived growth factor-induced signaling by mitogen-activated protein kinase in human arterial smooth muscle cells. Proc Natl Acad Sci USA 1993;90:10300-4.

93 Sevetson BR, Kong XM, Lawrence JC. Increasing cAMP attenuates activation of mitogen-activated protein kinase. Proc Natl Acad Sci USA 1993;90:10305-9.

94 Wu J, Dent P, Jelinek T, Wolfman A, Weber MJ, Sturgill TW. Inhibition of the EGF-activated MAP kinase signaling pathway by adenosine $3^{\prime}, 5^{\prime}$-monophosphate. Science 1993;262:1065-9.

95 Hafner S, Adler HS, Mischak H, Janosh P, Heidecker G, Wolfman A, et al. Mechanism of inhibition of Raf-1 by protein kinase A. Mol Cell Biol 1994;14:6696-703.

96 Frodin M, Peraldi P, Van Obberghen E. Cyclic AMP activates the mitogen-activated protein kinase cascade in PC1 2 cells. $\mathcal{F}$ Biol Chem 1994;269:6207-14

97 Vaillancourt RR, Gardner AM, Johnson GL. B-Raf dependent regulation of the MEK-1/mitogen-activated propendent regulation of the MEK-1/mitogen-activated pro-
tein kinase pathway in PC12 cells and regulation by cyclic tein kinase pathway in PC12 cells and reg

98 Stephens RM, Sithanandam G, Copeland TD, Kaplan DR, Rapp UR, Morrison DK. 95-kilodalton B-Raf serine/ threonine kinase: identification of the protein and its major autophosphorylation site. Mol Cell Biol 1992;12 3733-42.

99 Jaiswal RK, Mookied SA, Wolfman A, Landreth GE. The mitogen-activated protein kinase cascade is activated by B-Raf in response to nerve growth factor through inB-Raction with p21 Ras. Mol Cell Biol 1994;14:6944-53.

100 Choi KY, Satterberg B, Lyons DM, Elion EA. Ste5 tethers multiple protein kinases in the MAP kinase cascade remultiple protein kinases in the MAP kinase cascade re-
quired for mating in S. cerevisiae. Cell 1994;78:499-512.

101 Marcus S, Polverino A, Barr M, Wigler M. Complexes between STE5 and components of the pheromone-responsive mitogen-activated protein kinase module. Proc Natl Acad Sci USA 1994;91:7762-6.
102 Cherniack AD, Klarklund JK, Czech MP. Phosphorylation of the ras nucleotide exchange factor son of sevenless by mitogen-activated protein kinase. F Biol Chem 1994;269: $4717-20$.

103 Lee RM, Cobb MH, Blackshear PJ. Evidence that extracellular signal-regulated kinases are the insulin-activated Raf-1 kinase kinases. $f$ Biol Chem 1992;267: 1088-92.

104 Matsuda S, Gotoh Y, Nishida E. Phosphorylation of Xenopus mitogen-activated protein (MAP) kinase kinase by MAP kinase kinase and MAP kinase. F Biol Chem 1993 268:3277-81.

105 Brunet A, Pagès G, Pouysségur J. Growth factor-stimulated MAP kinase induces rapid retrophosphorylation and inhibition of MAP kinase kinase (MEK1). FEBS Lett 1994; 346:299-303.

106 Gardner AM, Vaillencourt RR, Lange-Carter CA, Johnson GL. MEK-1 phosphorylation by MEK kinase, Raf and mitogen-activated protein kinase: analysis of phosphopeptides and regulation of activity. Mol Biol Cell 1994; 5:193-201.

107 Takishima K, Griswold-Prenner I, Ingebritsen T, Rosner MR. Epidermal growth factor (EGF) receptor T669 peptide kinase from 3T3-Ll cells is an EGF-stimulated MAP kinase. Proc Natl Acad Sci USA 1991;88:2520-4.

108 Northwood IC, Gonzalez FA, Wartmann M, Raden DL Davis RJ. Isolation and characterisation of two growth factor-stimulated protein kinases that phosphorylate the epidermal growth factor receptor at threonine 669. $7 \mathrm{Biol}$ Chem 1991;266:15266-76.

109 Clarke PR. Switching off MAP kinases. Curr Biol 1994;4: $647-50$.

110 Sun H, Tonks NK. The coordinated action of protein tyrosine phosphatases and kinases in cell signalling. Trends tyrosine phosphatases and kin
Biochem $S_{c i} 1994 ; 19: 480-5$.

111 Sun H, Charles CH, Lau LF, Tonks NK. MKP-1 (3CH134), an immediate early gene product, is a dual specificity phosphatase that dephosphorylates MAP kinase in vivo. Cell 1992;75:487-93.

112 Brondello J-M, McKenzie FM, Sun H, Tonks NK, Pouysségur J. Constitutive MAP kinase phosphatase (MKP1) expression blocks $\mathrm{G} 1$ specific gene transcription and $\mathrm{S}$

113 Wu J, Lau LF, Sturgill TW. Rapid deactivation of MAP kinase in PC12 cells occurs independently of induction kinase in PC12 cells occurs independently of induction
of phosphatase MKP-1. FEBS Lett 1994;353:9-12.

114 Alessi D, Gomez N, Moorhead G, Lewis T, Keyse SM, Cohen $P$. Inactivation of p42 MAP kinase by protein phosphatase $2 \mathrm{~A}$ and a protein tyrosine phosphatase, but not CL100, in various cell lines. Curr Biol 1995;5:283-95. 